\title{
Imaging Findings of Children Stroke in Burkina Faso and Etiological Approach
}

\author{
Bénilde Marie Ange Tiemtore-Kambou, 1,2, Prosper Précieux Sagbohan², Dominique Bicaba3, \\ Nina-Astrid Nde-Ouedraogo 1,2, Zakari Nikiema ${ }^{3}$, Prosper David Lamien ${ }^{2}$, Adama Gnoumou ${ }^{4}$, \\ Ousséïni Diallo"1,5, Rabiou Cisse ${ }^{1,5}$
}

\author{
${ }^{1}$ Faculty of Health Sciences, Ouaga 1 Pr Joseph Ki-Zerbo University, Ouagadougou, Burkina Faso \\ ${ }^{2}$ Bogodogo Teaching Hospital, Ouagadougou, Burkina Faso \\ ${ }^{3}$ SanouSouroTeaching Hospital, Bobo-Dioulasso, Burkina Faso \\ ${ }^{4}$ Yati Clinic, Ouagadougou, Burkina Faso \\ ${ }^{5}$ Yalgado Ouedraogo Teaching Hospital, Ouagadougou, Burkina Faso \\ Email: kbenildema@yahoo.fr
}

How to cite this paper: Tiemtore-Kambou, B.M.A., Sagbohan, P.P., Bicaba, D., Nde-Ouedraogo, N.-A., Nikiema, Z., Lamien, P.D., Gnoumou, A., Diallo, O. and Cisse, R. (2019) Imaging Findings of Children Stroke in Burkina Faso and Etiological Approach. Open Journal of Radiology, 9 , 20-35.

https://doi.org/10.4236/ojrad.2019.91003

Received: October 25, 2018

Accepted: January 15, 2019

Published: January 18, 2019

Copyright $\odot 2019$ by author(s) and Scientific Research Publishing Inc. This work is licensed under the Creative Commons Attribution International License (CC BY 4.0).

http://creativecommons.org/licenses/by/4.0/

(c) (i) Open Access

\begin{abstract}
Introduction: Stroke is defined as a sudden onset focal neurological deficit of presumed vascular origin. Although it is essentially adult and elderly condition, stroke can occur in children. Their diagnosis essentially radiological is based on two main imaging modalities namely Computed Tomography (CT) and/or Magnetic Resonance Imaging (MRI). Our study aimed to study radiological features of stroke in children with an etiologic approach in three health facilities of Ouagadougou. Material and Method: We conducted a retrospective study with descriptive focus during 11-year period from January $1^{\text {st }}, 2006$ to September $1^{\text {st }}, 2017$ among children aged between 02 months and 16 years who underwent brain CT scan and/or MRI; in whom diagnosis of stroke had been established in radiology department of Yalgado Ouedraogo Teaching Hospital (CHU-YO), Schiphra Methodist Medical Center (CM Schipphra) and Saint Camille Hospital of Ouagadougou (HOSCO). Results: 40 cases of pediatric stroke were collected including 23 at HOSCO, 15 at $\mathrm{CHU}-\mathrm{YO}$ and 03 at CM Schipphra. Mean age was 6.45 years, with extremes of 2 months and 192 months. Unilateral contralateral motor weakness was the most common clinical presentation (32.5\%) followed by seizures (17.5\%). Ischemic stroke dominated in $82.5 \%$ of cases. Sino-venous thrombosis was rare and suspected in only one case. Sylvian artery was mostly affected in ischemic stroke for $56.25 \%$ of patients. The main etiologic factors found were hematologic $(67.50 \%)$ then infectious factors (25\%). Sickle cell disease was always incriminated in hematologic factor. Homozygous SS patients were the most numerous (82\%). Conclusion: Stroke diagnosis in children is based on
\end{abstract}


etiologic investigation, biology with a major role of medical imaging. Sickle cell disease accounts a lot in occurrence of stroke in children in our context.

\section{Keywords}

Stroke, Children, Brain CT/MRI, Ouagadougou, Burkina Faso

\section{Introduction}

Stroke is defined by World Health Organization (WHO) as "a clinical syndrome consisting of rapidly developing clinical signs of focal (or global in case of coma) disturbance of cerebral function lasting more than 24 hours or leading to death with no apparent cause other than a vascular origin" [1].

Although it is mainly adult and elderly disease, stroke can occur at any age notably in children.

Pediatric stroke is a relatively rare disease with an estimated incidence of 2.5 $13 / 100,000 /$ year [2]. Its mortality rate is about $0.6 / 100,000 /$ year [3] [4]. Child stroke has also serious morbidity and long-term outcome marked by its socio-psychological impact and costs particularly in our precarious context. From hence early diagnosis enabling specific treatment including thrombolysis or embolization is required to minimize occurrence of sequelae.

Stroke diagnosis in children is based on etiological investigation, laboratory tests and major role of medical imaging. Imaging modalities used in emergency are Computed Tomography (CT) and Magnetic Resonance Imaging (MRI). They help to confirm diagnosis, to determine type of stroke, to search etiology, to guide and participate in treatment, to recognize signs of severity, and to follow up.

However in our context, a particular cause is Sickle Cell Disease (SCD). Stroke is the most severe complication of SCD. Though Ogeng'o in Kenya noted a pediatric ischemic stroke prevalence of $56.3 \%$ compared to $43.7 \%$ of hemorrhagic stroke [5]. In Burkina Faso, Béré [6] noted ischemic CT lesions as cause of cerebral palsy in child with a frequency of $6.7 \%$. No studies have been done on pediatric stroke in our context.

We propose to study radiological features of stroke in children with an etiological approach.

\section{Patients and Methods}

We conducted a descriptive retrospective study from January $1^{\text {st }}, 2006$ to September $1^{\text {st }}, 2017$, in radiology departments of Yalgado Ouedraogo Teaching Hospital (CHU-YO), Schiphra Protestant Medical Center and Saint Camille Hospital of Ouagadougou (HOSCO) of Burkina Faso.

This study concerned children from 02 months to 16 years old who underwent head CT scan and/or MRI in one of the three health facilities previously 
mentioned and for whom diagnosis of stroke had been established. We have expressly excluded children under two months because of challenge in achieving and obtaining results of a brain CT/MRI scan in our context of those children (sedation requirement) and also predominance of obstetric and perinatal causes.

For head CT exam, we used GENERAL ELECTRIC HISPEED 08 slices machine at Schiphra Protestant Medical Center, SIEMENS SOMATOM EMOTION 32 slices and 64 slices devices respectively at $\mathrm{HOSCO}$ and CHU-YO.

Complementary brain MRI scan were performed at HOSCO using a SIEMENS MAGNETOM ESSENZA 1.5 Tesla device.

Images were reported by a senior radiology consultant.

Useful information was collected via data collection forms. Variables of our study were:

- Epidemiological: age, sex, educational levels;

- Clinical: neurological symptoms, general signs;

- Radiological:

- Imaging modalities;

- Type of stroke;

- Spontaneous hyperdensity (location, volume, intraventricular hemorrhagic flood, subarachnoid hyperdensity, brain herniation);

- Hypodense area (localization, vascular territory;

- Early CT signs of ischaemic stroke: cortical hypo density with associated parenchymal swelling with resultant gyral effacement (e.g. insular ribbon sign), loss of grey-white matter differentiation, and hypo attenuation of deep nuclei, hyper dense segment of a vessel;

- Hyperdensity within a thrombosed sinus;

- Etiological factors: hematological, infectious, cerebral, cardiac, surgical.

For patients diagnosed of stroke, data was collected from TDM and/or MRI scans records and patient interviews available.

Data analysis was performed on Windows 7 computer using Excel statistical tools for data entry and Epi Info for processing. MRI images were viewed on Radiant Dicom 32-bit viewer software.

Data collection was managed in anonymity and absolute confidentiality. The study was conducted with authorization of Head of Department in the three health centers.

\section{Results}

There were 3482 cerebral CT scans performed between 2006 and 2017 in the three health centers, and 174 brain MRI exams performed between 2013 and 2017 at HOSCO which had established stroke diagnosis.

A total of 40 children aged from 2 months to 16 years had a diagnosis of stroke on CT and/or MRI, which represents $1.14 \%$ of CT scans. Among them, 23 (57.5\%) were followed up at HOSCO, 15 (37.5\%) at CHU-YO and $03(5 \%)$ at Schiphra Protestant Medical Center. 
Mean age of patients was $77.55 \pm 57.75$ months, or 6.45 years with interval ends of 2 and 192 months. The most represented age group were children over 5 (60 months) counting $55 \%$ of all (Figure 1).

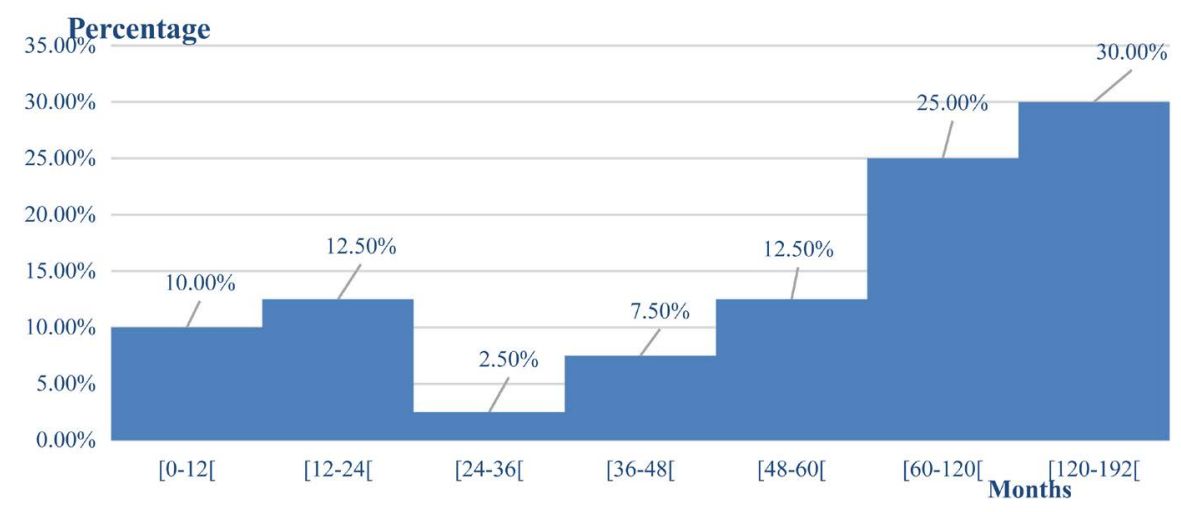

Figure 1. Distribution by age group.

Male sex was dominant in $57.50 \%$ of cases $(n=23)$. Sex ratio was 1.35 .

Distribution of patients by clinical signs was summarized on Table 1 .

Table 1. Distribution of patients by clinical signs.

\begin{tabular}{cc}
\hline Clinical sign & Size \\
\hline Coma & 2 \\
Lethargy & 1 \\
Mental retardation & 1 \\
Aphasia & 1 \\
Headache & 3 \\
Seizures & 7 \\
Unilateral contralateral motor weakness & 13 \\
Fever & 1 \\
General state worsening during acute sickle cell crisis & 1 \\
Abnormal ballet movements & 1 \\
Repeated loss of consciousness & 2 \\
Psychomotor delay & 1 \\
Amnesia & 5
\end{tabular}

Unilateral contralateral motor weakness was the most frequent sign $(\mathrm{n}=13)$ followed by tonic-clonic seizures $(n=7)$ and psychomotor delay $(n=4)$.

All 40 patients underwent brain CT scan. Complementary MRI was performed by 03 patients or $7.5 \%$ of cases. Figure 2 shows distribution of TDM examinations by year. The highest rate of performing CT scan was observed in 2015 and 2017. 


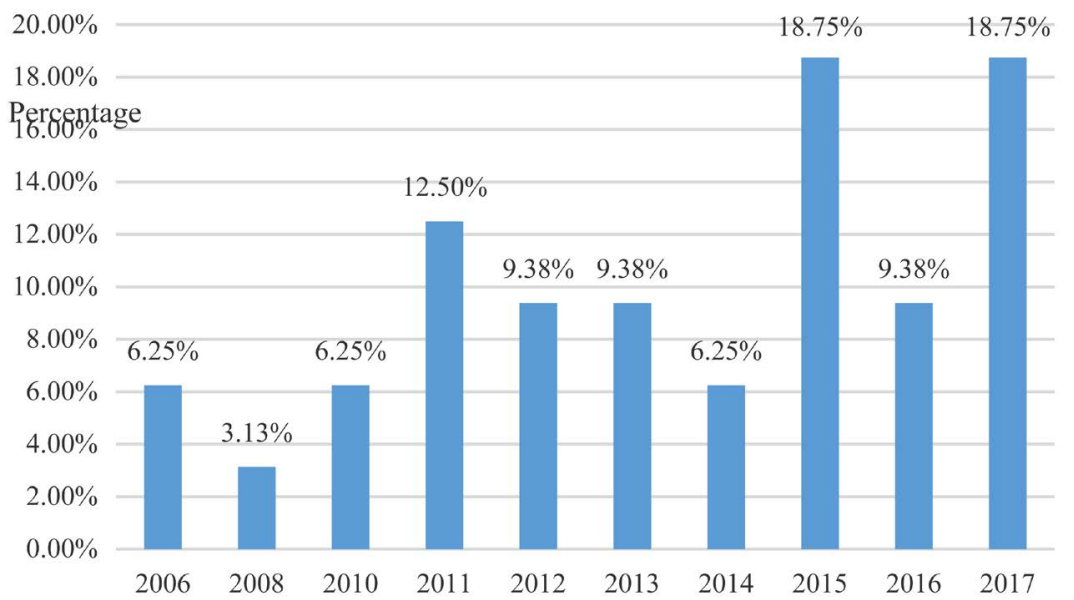

Figure 2. Distribution of brain CT scan examination by year.

Ischemic stroke dominated in $82.5 \%$ of cases ( $\mathrm{n}=33$ patients) followed by hemorrhagic stroke in $15 \%(n=6)$. Sino-venous thrombosis was rare suspected in one child $(\mathrm{n}=1)$.

Three patients (7.5\%) CT scans demonstrate area of intracerebral hyperdensity representing hematoma. Two were located in left frontal and left temporal lobes; the third in right parietal lobe. Figure 3 illustrates these hematomas. There was no brain herniation or meningeal irritation associated with these hematomas.

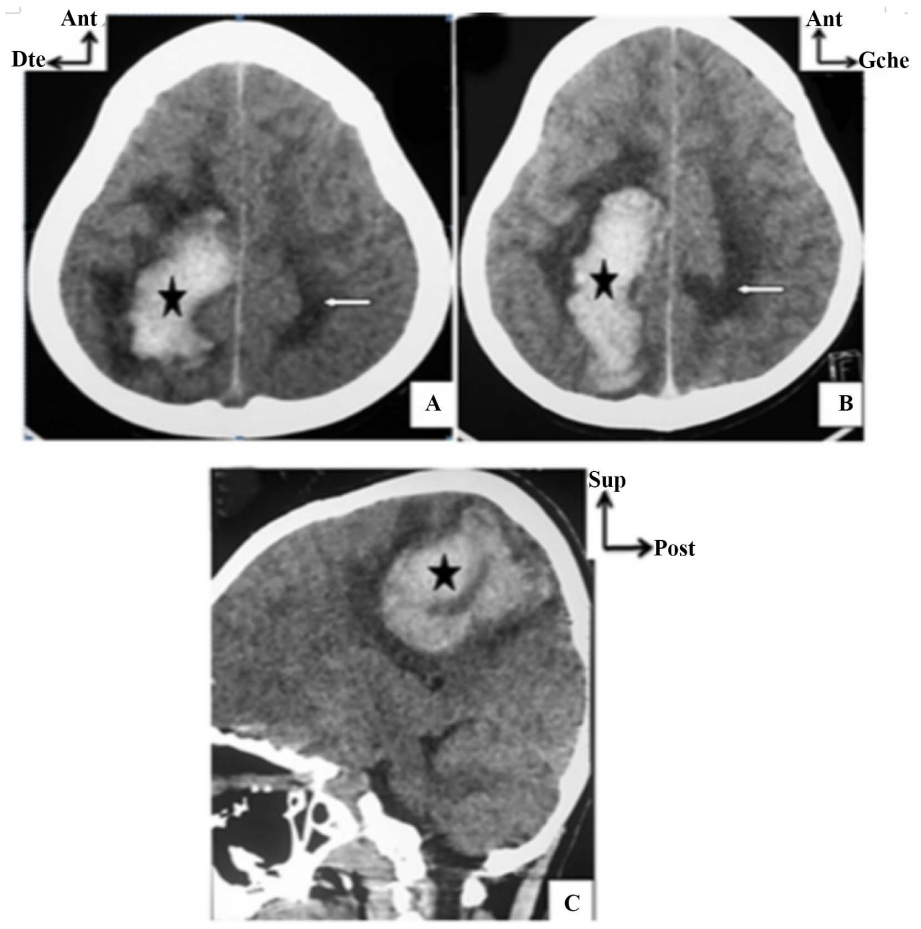

Figure 3. Non contrast Brain CT scan showing an oedemato-haemorrhagic lesion (black star) of $32 \mathrm{ml}$ in right parietal lobe without mass effect and associated with contralateral edema (white arrow) observed in a 72-month-old child with no particular pathological history received in comatose state after onset of left hemiparesis and amnesia. Views: axial (A) and (B); coronal reconstruction (C). 
Subarachnoid hyperdensities were observed in 4 patients. Figure 4 shows a case of subarachnoid hemorrhage.
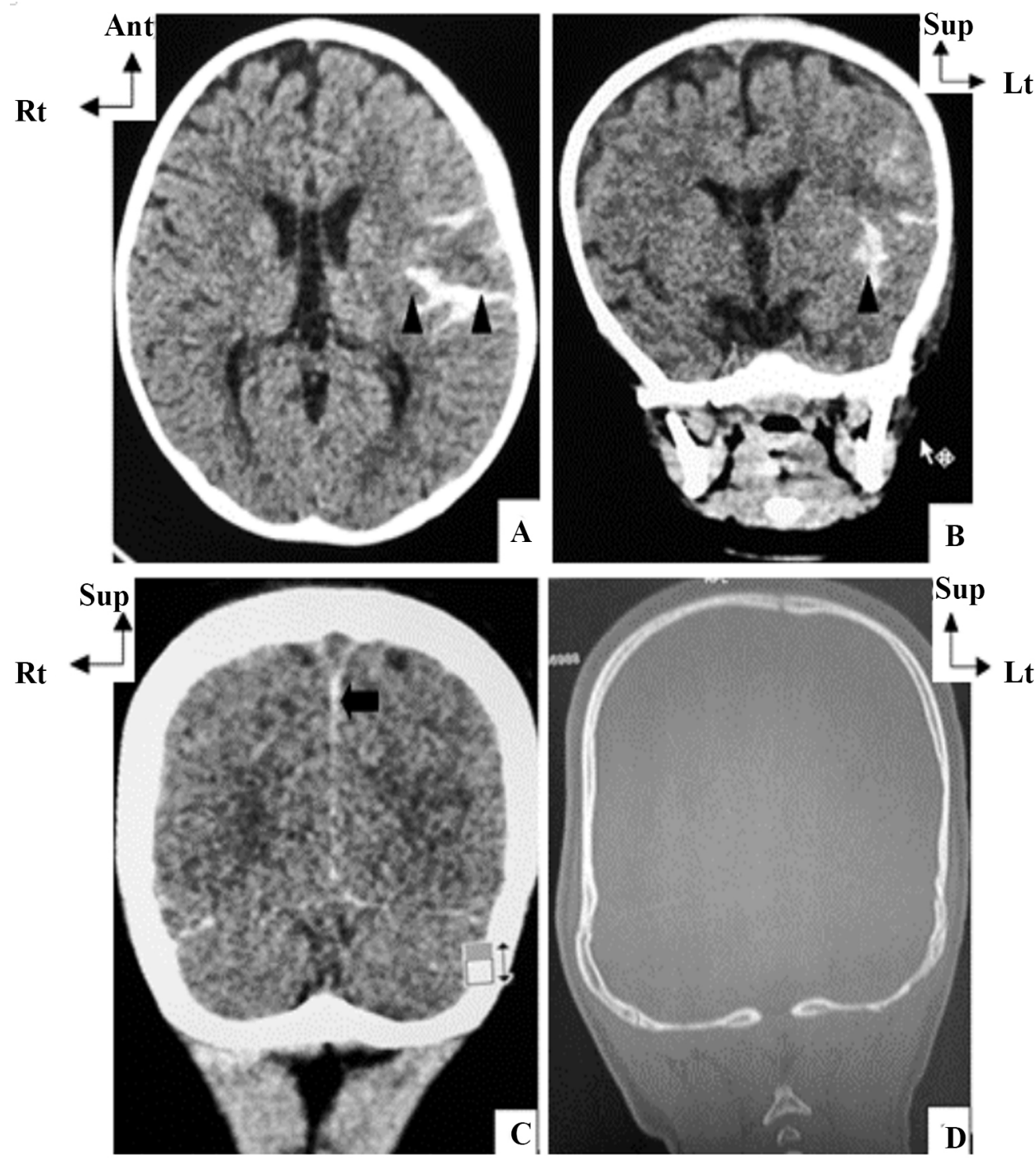

Figure 4. Non contrast brain CT scan of a 03-year-old patient after head trauma with initial loss of consciousness. Noted is hyper attenuating material filling left temporal subarachnoid spaces (black arrowhead) and falx cerebri (black arrowhead) in keeping with subarachnoid hemorrhage. No evidence of adjacent fracture on bone window (D). Axial view (A); Coronal reconstruction (B), (C) and (D).

$34(85 \%)$ patients had one or more intracerebral hypo attenuated including one suspected case of cerebral venous thrombosis. $32.3 \%$ of them were found in right hemisphere and $47.1 \%$ in left hemisphere. $20.6 \%$ cases demonstrated bilateral hemisphere involvement.

Superficial middle cerebral artery (MCA) was most affected in 10 (31.25\%) patients followed by deep MCA in 8 (25\%) and border zones ischemic stroke between MCA and ACA concerning 2 cases.

Figures 5-7 show CT features of these hypodensities. 


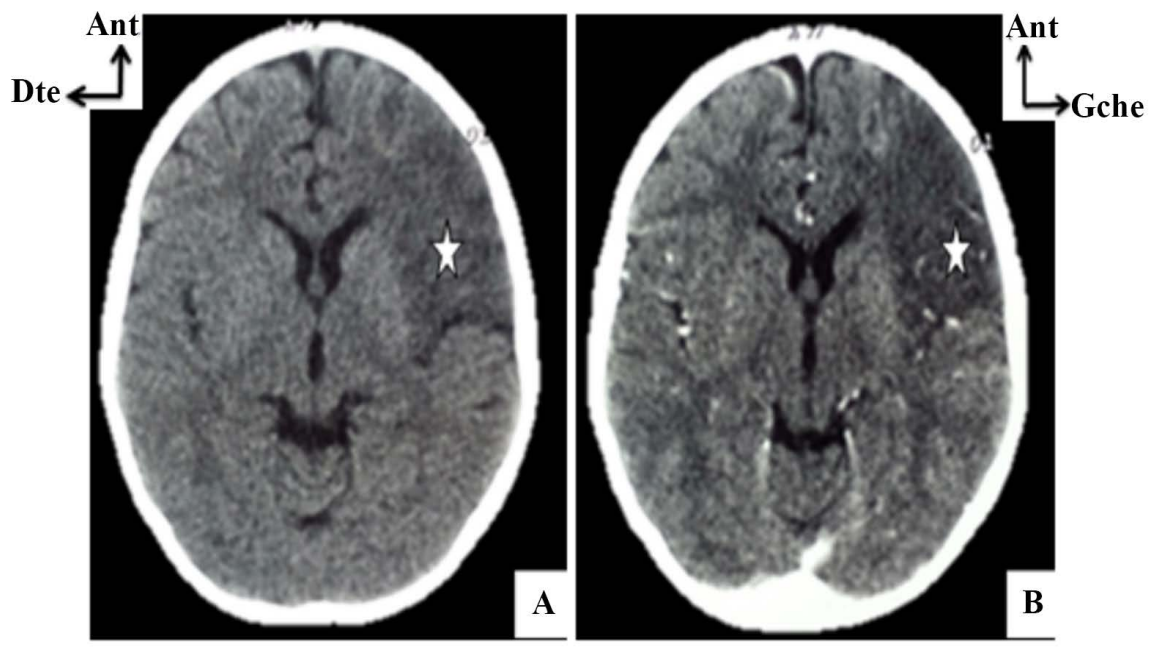

Figure 5. Brain CT scan performed in a 07-year-old, homozygous SS patient, demonstrating left fronto-temporal area of hypodensity (white arrow) related to ischemic stroke in left superficial territory of MCA, no enhancing after intravenous contrast injection. Axial views: (A) No contrast; (B) Contrast.

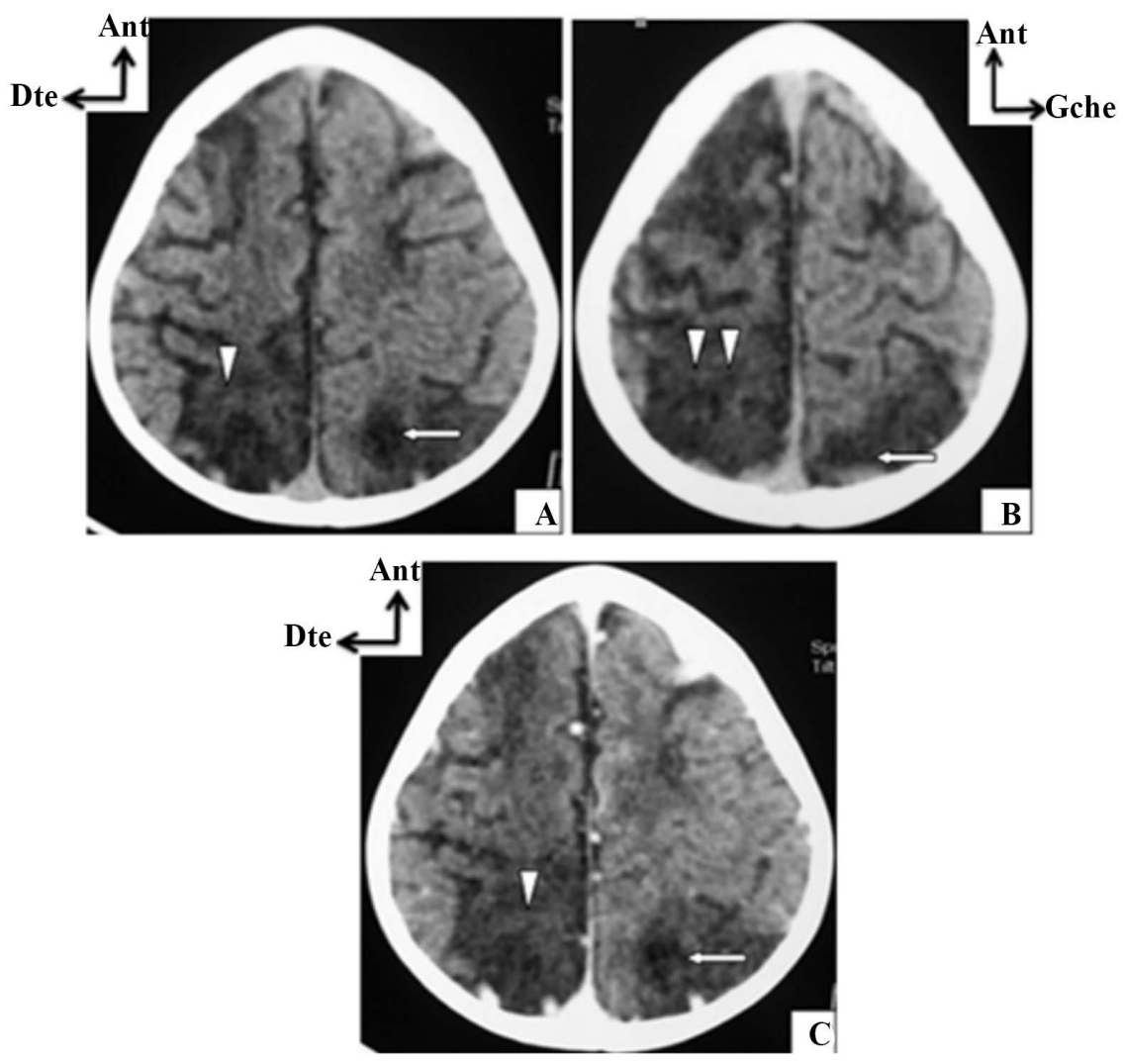

Figure 6. Brain CT scan of a 02 years-old patient admitted for left flasquo-spasmodic hemiparesis evolving since 03 weeks in a context of tetralogy of Fallot. Noted are: -right fronto-parieto-occipital hypo attenuated area (white arrowhead $\mathrm{AB}$ ), non-enhancing (C. white arrowhead) without mass effect in keeping with subacute ischemic stroke in junctional territory (right ACA, MCA and PCA); -left parieto-occipital hypodense area of chronic infarct (A. B. white arrow), non-enhancing (C. white arrowhead). Axial views: (A) and (B) no contrast; and (C) contrast. 


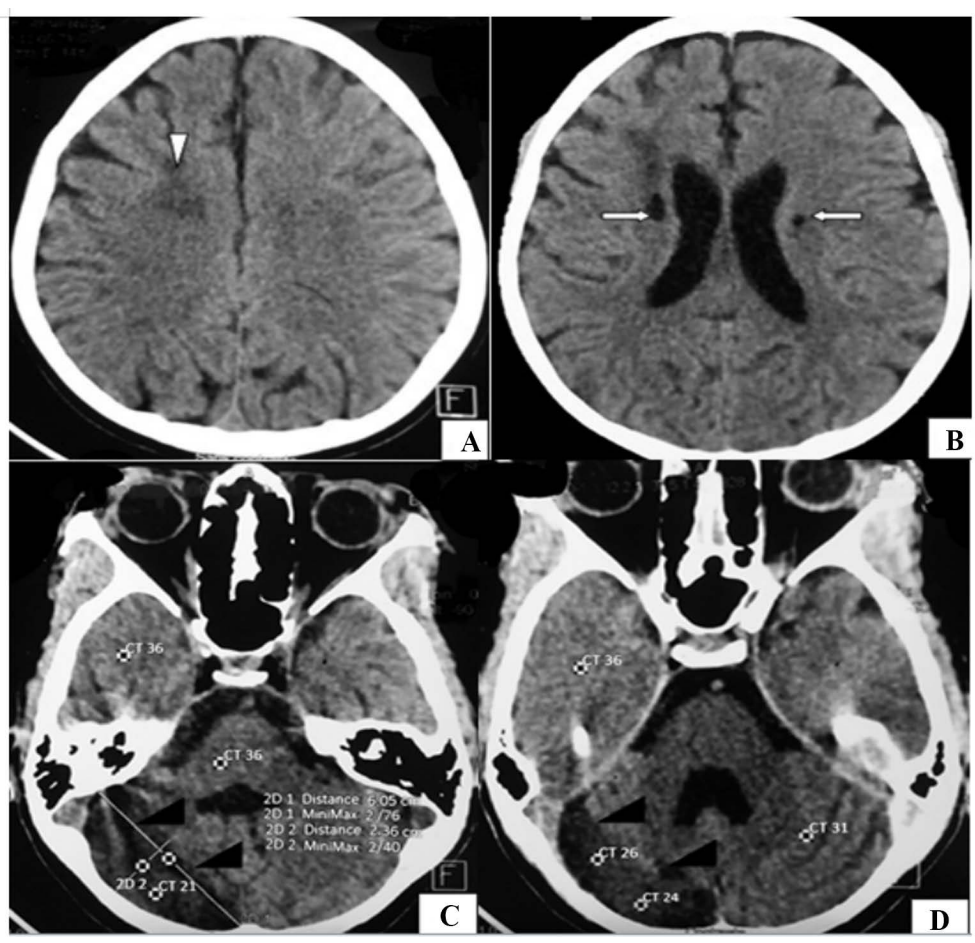

Figure 7. Brain CT scan of a 15-year-old, homozygous SS patient received for left hemiparesis and seizures showing multiple infarcts: -hypodense area of right centrum semiovale related to subacute ischemic stroke (A. white arrowhead); -bilateral internal capsule lacunar infarcts (B. white arrows) associated with brain atrophy; -right cerebellar hemisphere hypo attenuated area on its posterior slope in keeping with an infarct in the upper, middle and lower territories of the right cerebellar artery (C. D. black arrowheads). Non contrast axial views: (A), (B), (C) and (D).

Hyperdensity within a cerebral artery was found in two patients.

Table 2 presents associated CT signs of our patients. Cerebral atrophy was frequently associated in 12 patients.

Table 2. Others associated CT findings to infarcts.

\begin{tabular}{cc}
\hline CT Findings & Number \\
\hline Subarachnoid enhancement & 1 \\
Calcifications & 4 \\
Brain atrophy & 12 \\
Extra-axial fluid collection & 1 \\
Brain edema & 1 \\
Feeding by superficial artery & 1 \\
Subfalcine mid-line shift & 1 \\
Ventricular hemorrhage & 1 \\
Tentorium cerebelli subarachnoid hemorrhage & 1 \\
Recurrent infarction & 1 \\
Total & 1 \\
\hline
\end{tabular}


Brain MRI was performed in 03 patients (7.5\%) and ischemic stroke or sequellae of ischemic stroke had been diagnosed in all cases.

These MRI features are shown on Figures 8-10.

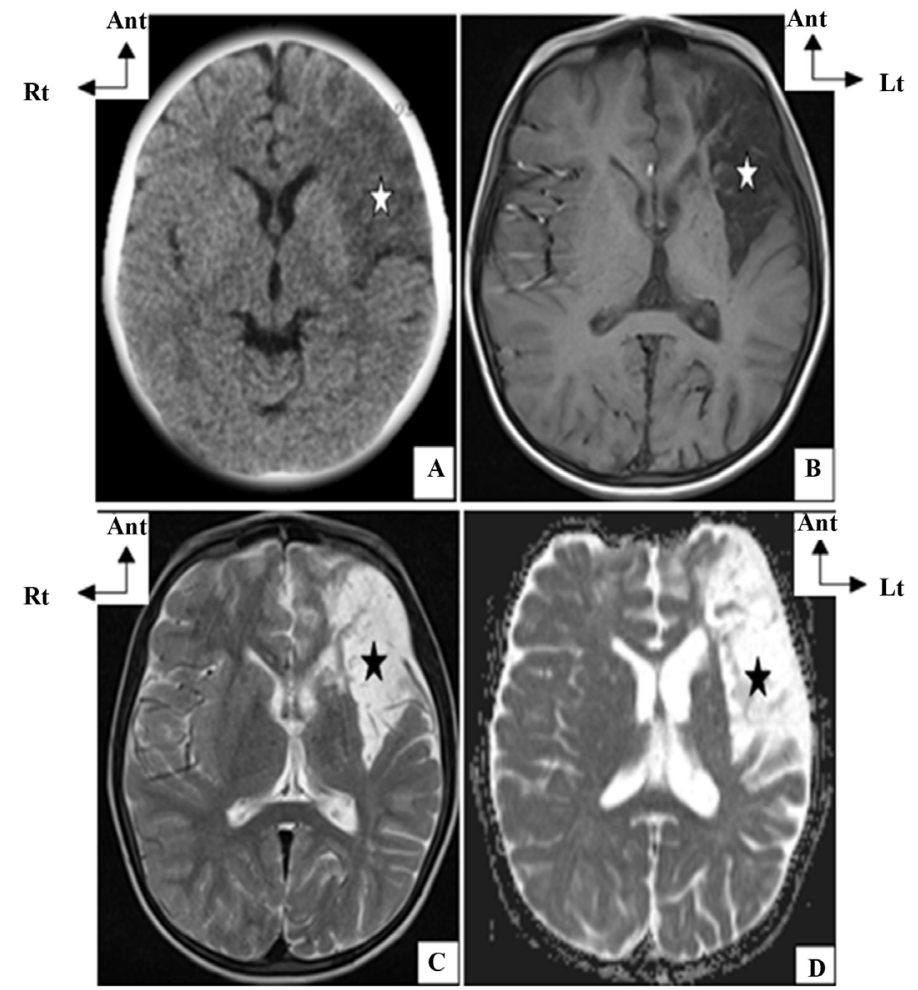

Figure 8. Brain CT scan showing left fronto-temporal hypo attenuated area (A, white star) and conjoined brain MRI scan noted T1 hyposignal area (B, white star), T2 hypersignal (C, black star), and hypersignal diffusion (D, black star) in a 07-year-old male, homozygous SS patient with right hemiplegia, in keeping with ischemic stroke in left superficial Sylvian territory. (A) CT axial view; (B) MRI axial view T1 W; (C) MRI axial view T2 W; (D) MRI DWI.

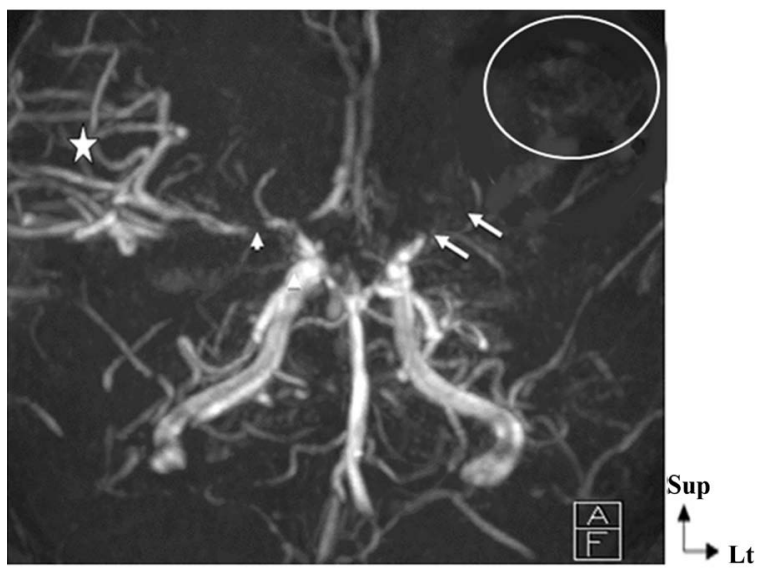

Figure 9. 3D TOF Angio MRI in coronal reconstruction of Willis circle in the same patient showing: -Complete thrombosis of M1 segment of left MCA (white arrows); its distal branches are no longer visualized (white circle); -Partial thrombosis of M1 segment of right MCA (white arrowhead) with reperfusion of its distal branches (white star). 

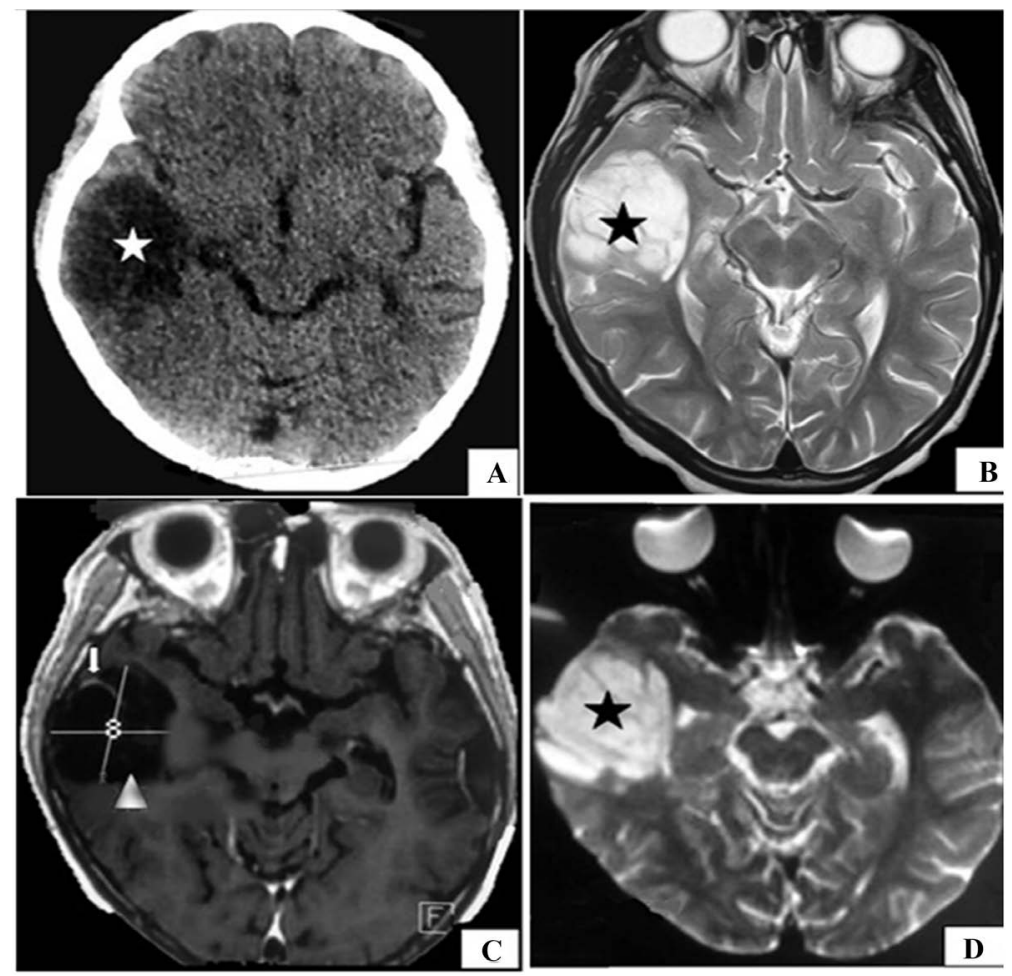

Figure 10. Brain CT scan performed in a 08-year-old girl with Sickle Cell Disease admitted for seizures with no specific pathological history showing right temporal area of hypodensity (A. white star); and conjoined MRI scan noted a multi located fluid appearance lesion in hypersignal T2W and Diffusion (B. D. black stars), hyposignal T1W + Gd (C. head of arrow) drained by a cortical vein (C. white arrow). This lesion suggests atypical porencephalic cavity in keeping with stroke sequellae. (A) CT non-contrast axial view; (B) MRI T2W axial view; (C) MRI T1W + Gd axial view; (D) MRI Diffusion sequence.

Etiological investigation was made in 30 (75\%) patients. Figure 11 shows distribution of patients by risk factors and etiologies.

\section{Number}

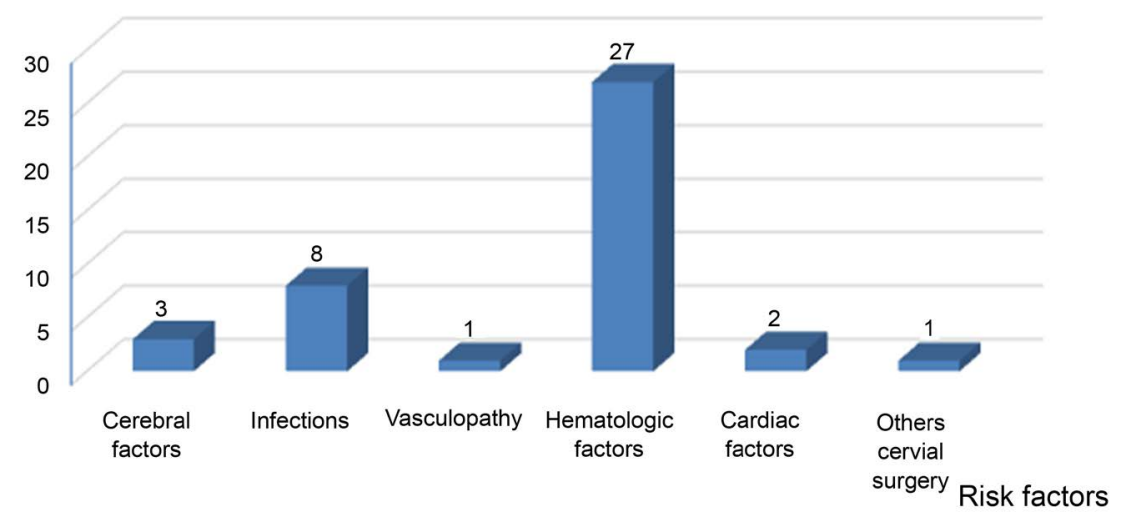

Figure 11. Distribution by risk factors.

Hematologic factors were dominant $(\mathrm{n}=27)$ followed by infectious factors ( $\mathrm{n}$ $=8)$. 
Sickle cell disease was the main hematological factor. Homozygous SS patients were frequently seen in $82 \%$ of cases followed by SC heterozygotes (11\%) and thalassemic patients (7\%).

Cardiovascular factors observed were tetralogy of Fallot $(n=1)$, inter-atrial communication $(\mathrm{n}=1)$ and high blood pressure $(\mathrm{n}=1)$.

Chickenpox was mentioned as history in $06(15 \%)$ patients. Delay between these episodes of varicella and stroke onset could not be clearly determined by parents. Other associated risk factors were mentioned including a case of meningoencephalitis and a case of encephalitis.

Cerebral factors observed were brain trauma $(\mathrm{n}=1)$, cerebral angioma $(\mathrm{n}=1)$ and AVM $(n=1)$. Figure 12 depicts AVM case.

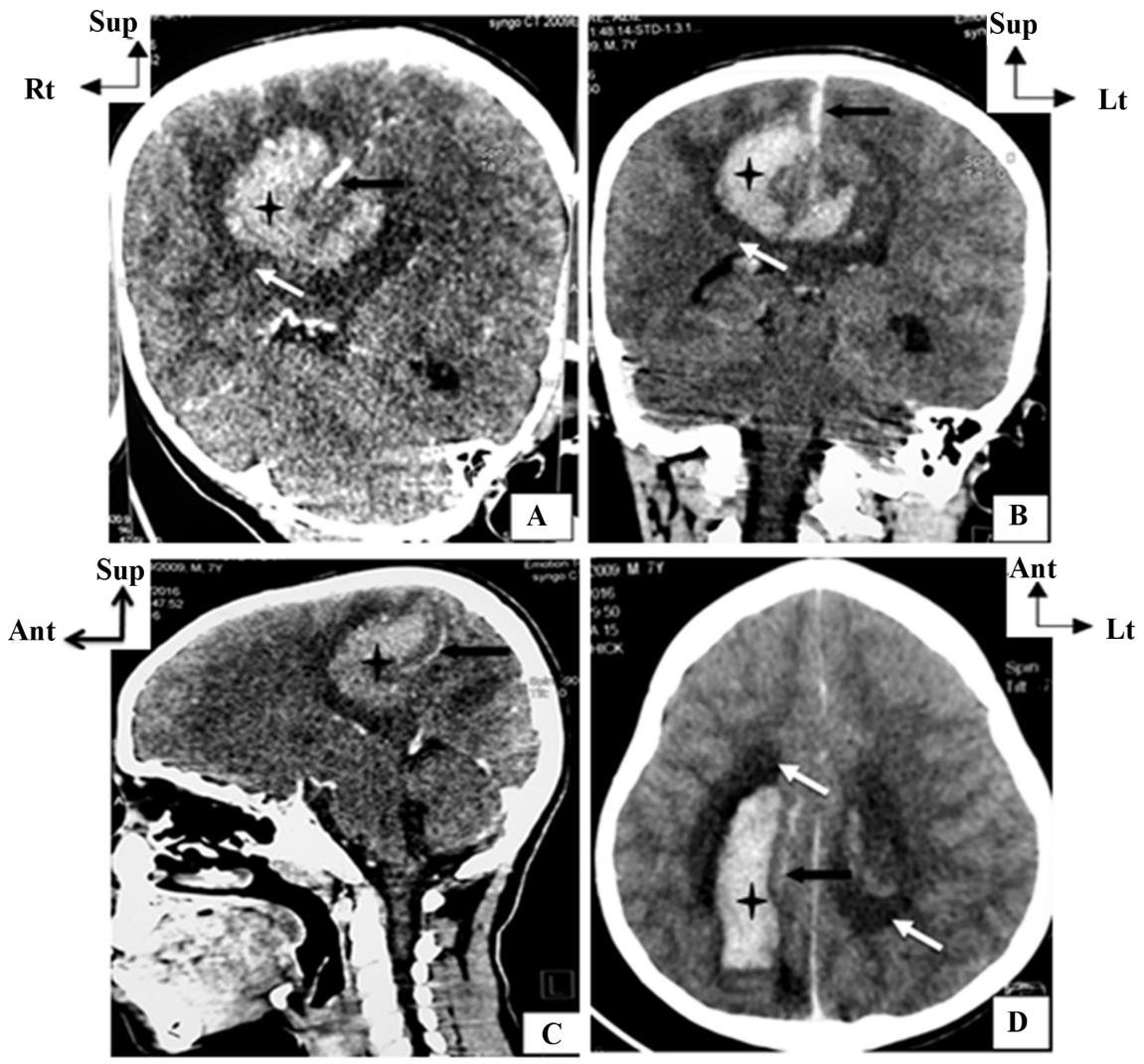

Figure 12. Brain CT scan with contrast in a 07 years-old patient showing: -Right parietal edemato-hemorrhagic lesion (A.B.C.D, black star); -Inside this lesion, there is feeding superficial parietal artery and veinous drainage through cortical veins towards superior longitudinal sinus and internal cerebral vein (A.B.C.D, black arrows); -Peripheric and contralateral white matter edema (A.B.C.D, white arrows). These characters are in keeping with bleeding of an arteriovenous malformation. (A) and (B) coronal reconstruction; (C) sagittal reconstruction, (D) axial view.

We noticed a case of ischemic stroke after cervical vascular tumor surgery in a 16-year-old teenager. Follow-up has been favorable for most patients. We did not register any deaths. Sequellae were observed in 04 patients including one case of limping and three cases of mental retardation. 


\section{Discussion}

Study on radiological features of stroke in children with etiological approach is a first onset in Burkina Faso. Our study faced some difficulties.

- Indeed, it is a relatively rare pathology in children unlike adults.

- No studies were conducted on that subject in Burkina Faso.

- Stroke diagnosis requires imaging devices, notably CT and MRI, which have recently established in certain health facilities in Ouagadougou. The high cost of these imaging modality prior to onset of free care management of less than 5 years patients has limited size of our sample.

- Use of patient's folders has been difficult due to poor archiving and preservation of CT/MRI images by both parents and Pediatric department.

Our study has, however, leaded results that raised comments and discussion.

According to several studies, stroke is less common in children than in adults

[7] [8] [9]. We were able to enroll 40 children aged 2 months to 16 years during 11 -years period from 2006 to 2017. This number corroborates literature data estimating the annual incidence of child strokes between 1.3 to 13 years for 100,000 children-years [10]. Mean age of our patients was 6.45 years. Sagna, Lengue and Steinlin [8] [9] [11] found younger age groups (less than 5 years). This could be explained by predominance in their study of para-infectious and infectious risk factors whose peak is at preschool years. Male predominance found is consistent with literature data [5] [7] [9] [11] [12]. According to Steinlin and al, for unknown reasons, stroke is twice as likely in boys as in girls [11]. However, literature remains controversial with some studies that find female predominance [13].

Clinical presentation of stroke in our sample is predominantly marked by deficient hemi-corporeal motor. This sign was also found in some studies where hemiplegia prevalence could reach $70 \%$ to $80 \%$ [5] [7] [9] [11] [12]. This hemiplegia was followed closely by seizures in our series as well as in some literature data [14]. Non-focal deficient symptoms likely headache (7.5\%), disturbances of consciousness (12.5\%), psychomotor retardation (12.5\%) were also identified as clinical presentation of child stroke [15].

Brain CT scan had been performed in 18, 75\% of patients in 2015 and 2017. This peak in 2017 could be explained by success of free care to children under 05 in our health policy.

In opposite, brain MRI scan performing is very low (7.5\%) as it is not free despite the fact that it is the gold standard in stroke diagnosis. Among the three health facilities of our cohort, only HOSCO which is a private center is fitted with a 1.5 tesla MRI machine and the cost of brain MRI scan is 100,000 XOF. Despite its weak performing in our study, contribution of MRI is undeniable.

Predominance of ischemic stroke (82.5\%) compared to other types of stroke, particularly hemorrhagic stroke (15\%), corroborates results of a US study [16] based on follow-up of 4000 patients during 10 years which found that ischemic stroke occurs mainly before 20 with high-level risk between 1 and 9 years while 
hemorrhagic stroke is mostly seen after 20 .

Ischemia was located firstly in sylvian artery territory (56.25\%) as found by Sagna [9], Ogeng'o [5], Tohodjèdé [12] and Ndiaye [7]. This topographic distribution is related to a particular architecture of vascular tree for brain. In fact, MCA is the widest and most direct branch of the endings of internal carotid artery; therefore it leads to receive the most emboli [17] [18] [19] [20].

Cerebral atrophy was the most associated CT sign in our sample (30\%). For some authors, it could be a risk marker for ischemic stroke or intracranial hemorrhage and could explain cognitive disorders seen with some patients [20] [21].

In our study main etiologies involved in stroke were hematological factors (67.50\%) followed by infectious factors (25\%) and cerebral factors (20\%). Some African studies found similar results [5] [7] [9] [11] [12] with hematologic factors ranked first. The main etiological and hematological factor found was homozygous SS of sickle cell disease (82\%). This important source of cerebral infarction in children [22] [23], is commonly seen in sub-Saharan African population. From our study, we noted that sickle-cell child developed stroke around 6.8 years. This data could help in stroke prevention. In fact, sickle cell disease increases risk of cerebral infarction by 200 to 400 [12] [15]. Therefore stroke is one of the most serious complications of sickle cell disease which requires adequate management including early detection for better monitoring to avoid subsequent complications such as cerebral vasculopathy. Chung in China [24] didn't find any case of sickle cell disease in his cohort; this difference could be related to the high prevalence of sickle cell disease in Africa and particularly in its black population. Sickle cell disease is also known to increase the risk of stroke recurrence. Elsewhere a study based on Chinese children recorded rather central nervous system infections, Moyamoya disease and head trauma as main causes of pediatric stroke [25].

Cardiac embolism is thought to account for $3.7 \%$ to $33.3 \%$ of ischemic stroke [7] [9] [10] [11] [12] [20]. In our patient group, we mainly found congenital heart diseases such as tetralogy of Fallot and atrial septal defect, unlikely to SALIH's study in Saudi Arabia where it was acquired rheumatic heart disease [26]. Acquired rheumatic heart disease is a common post-streptococcal complication. Is their rarity in our study due to good management of group A post-streptococcal disorders in children?

Cerebral risk-factors have also been found in literature [13] [14]. According to Béjot [14], main cause of intracranial hemorrhage in children is arteriovenous malformation (AVM) rather than high blood pressure that is observed in adult. They account for between $14 \%$ and $57 \%$ of all brain bleeding causes depending on studies and annual risk of cerebral hemorrhage in children with AVM is about 3\%. Angioma, which has been poorly screened before arrival of MRI, could however represent up to $25 \%$ of cases of cerebral hemorrhage [14].

We did not notice any deaths in our series. Lengue [8] reported a mortality 
rate of $0.92 \%$ that was the lowest of $4 \%$ to $28 \%$ [8] [27]. However, this absence of death is subject to the 10 patients who could not be reached during interview because of wrong number in CT and MRI report registers.

In our cohort, 04 patients had long-term sequellae such as lameness and mental retardation. Ndiaye [7] and Tohodjèdé [2] obtained similar results. These stroke sequellae are current in literature [14]. The observed sequellae are numerous and could increase socio-economic impact of this pathology especially in our countries with limited resources and affect severely prognosis of these children.

\section{Conclusion}

Pediatric stroke is predominantly ischemic with sickle-cell disease as main cause. $\mathrm{CT}$ is first-line imaging modality and contributes a lot in stroke diagnosis in our context. However, MRI which is the gold standard imaging modality in this investigation is poorly used in Burkina Faso. Etiological predominance of sickle cell disease suggests implementation of adequate prevention measures to control this pathology. In addition, the prevention of stroke recurrence with hematologic etiology is based on establishment of blood transfusion program aimed at lowering S Hemoglobin level and decreasing cerebral arteries velocity on transcranial Doppler scan. This technique is not yet implemented in our context. Future prospective studies on the contribution of this transfusion program to the secondary prevention of stroke in sickle cell patients are therefore necessary.

Further prospective study on contribution of this blood transfusion program in stroke prevention of sickle cell's patients is therefore needed.

\section{Conflicts of Interest}

The authors declare no conflicts of interest regarding the publication of this paper.

\section{References}

[1] World Health Organization (2001) The World Health Report 2001: Mental Health: New Understanding, New Hope. World Health Organization, Genève. 100 p. http://www.who.int/iris/handle/10665/42390

[2] Paonessa, A., Limbucci, N., Tozzi, E., Splendiani, A. and Gallucci, M. (2010) Radiological Strategy in Acute Stroke in Children. European Journal of Radiology, 74, 77-85. https://doi.org/10.1016/j.ejrad.2009.01.016

[3] Fullerton, H., Elkins, J. and Johnston, S. (2004) Pediatric Stroke Belt: Geographic Variation in Stroke Mortality in US Children. Stroke, 35, 1570-1573. https://doi.org/10.1161/01.STR.0000130514.21773.95

[4] Arias, E., Anderson, R.N., Kung, H.C., Murphy, S.L. and Kochanek, K.D. (2003) Deaths: Final Data for 2001. National Vital Statistics Reports, 52, 1-115. https://www.cdc.gov/nchs/data/nvsr/nvsr52/nvsr52_03.pdf

[5] Ogeng'o, J., Beda, O., Mburu, A. and Simeon, R. (2010) Pediatric Stroke in African Country. Journal of Pediatric Neurosciences, 5, 22-24. https://doi.org/10.4103/1817-1745.66676 
[6] Béré, D. (2016) Cerebral Palsy in Children Aged 0 to 15 in Ouagadougou: Epidemiological, Clinical and Therapeutic Aspects. Doctoral Thesis, Ouaga-I $\mathrm{P}^{\mathrm{r}}$ Joseph KI-ZERBO University.

[7] Ndiaye, M., Sow, A., Seck, L., Sami, O., Toure, K., Basse, A., et al. (2013) Children Ischemic Stroke in Senegal: Clinical, Paraclinical and Progressive Aspects. Journal of Pediatric Neurology, 11, 9-13.

[8] Lengue, M. (2016) Children Ischemic Stroke at Fann Teaching Hospital of Dakar. Doctoral Thesis, Cheikh Anta Diop University, Dakar.

[9] Sagna, S. (2015) Children Ischemic Stroke at Dakar Teaching Hospital. Neurology Dissertation, Cheikh Anta Diop University, Dakar.

[10] Hervieu-Begue, M., Jacquin, A., Kazemi, A., et al. (2012) Stroke in Children: A Medical Emergency. Medical Press, 41, 518-524.

[11] Steinlin, M. and Wehrli, E. (2009) Ischemic Stroke in Pediatrics. When to Think about It-What To Do? Paediatrica, 20, 22-26. http://www.swiss-paediatrics.org/paediatrica/vol20/n2/pdf/22-26.pdf

[12] Tohodjèdé, Y., Bonou, O., Lalya, F., Nguefack, S., Houannou, V., Yèkpè, P., et al. (2018) Children's Stroke: Epidemiological, Diagnostic and Evolutionary Aspects in Cotonou (Benin). Sub-Saharan Medecine, 65, 13-20.

[13] Bowen, M., Burack, C. and Barron, T. (2005) Childhood Ischemic Stroke in a Non-Urban Population. Journal of Children Neurology, 20, 194-197. https://doi.org/10.1177/08830738050200030501

[14] Béjot, Y., Chantegret, C., Osseby, G., Chouchane, W., Huet, F., Moreau, T., et al. (2009) Newborn and Children Stroke. Neurologic Review, 16, 889-900. https://doi.org/10.1016/j.neurol.2009.01.039

[15] Mackay, M., Wiznitzer, M., Benedict, S., Lee, K., Deveber, G., Ganessan, V., et al. (2011) Arterial Ischemic Risk Factors: The International Pediatric Stroke Study. Annals of Neurology, 69, 130-140. https://doi.org/10.1002/ana.22224

[16] Earley, C., Kittner, J., Feeser, R., Gardner, J., Epstein, A., Wozniak, M., et al. (1998) Stroke in Children and Sickle-Cell Disease: Baltimore-Washington Cooperative Young Stroke Study. Neurology, 51, 169-176.

https://www.ncbi.nlm.nih.gov/pubmed?term=9674798\%5Buid\%5D\&cmd https://doi.org/10.1212/WNL.51.1.169

[17] Lynch, J. and Han, C. (2005) Pediatric Stroke: What Do We Know and What Do We Need to Know? Seminars in Neurology, 25, 410-423. https://doi.org/10.1055/s-2005-923535

[18] Osborn, G., Susan, I., Hedlund, G., et al. (2013) Diagnostic Imaging Brain. First Edition, Second Printing, Amirsys Inc., Salt Lake City.

[19] Arrive, L. (2007) MRI Practice. Medical Imaging Collection-Practice. Masson Edition, France.

[20] Desal, H.A., Auffray-Calvier, E., et al. (2004) Emergency Imaging of Cerebrovascular Accidents. Journal of Neuroradiology, 31, 327-333. https://www.ncbi.nlm.nih.gov/pubmed/?term $=15545944$ https://doi.org/10.1016/S0150-9861(04)97011-3

[21] Lanni, G., Catalucci, A., Conti, L., Di Sibio, A., Paonessa, A. and Gallucci, M. (2011) Pediatric Stroke: Clinical Findings and Radiological Approach. Stroke Research and Treatment, 2011, Article ID: 172168.

[22] Benatru, I., Rouaud, O., Durier, J., Contegal, F., Couvreur, G., Bejot, Y., et al. (2006) Stable Stroke Incidence Rates but Improved Case-Fatality in Dijon, France, from 
1985 to 2004. Stroke, 37, 1674-1679.

https://doi.org/10.1161/01.STR.0000226979.56456.a8

[23] Verlhac, S. (2007) Pediatric Stroke. Journal de Radiologie, 88, 1453. https://doi.org/10.1016/S0221-0363(07)81397-7

[24] Brian, C. and Wong, V. (2004) Pediatric Stroke among Hong Kong Chinese Subjects. Pediatrics, 114, e206-e212. https://www.ncbi.nlm.nih.gov/pubmed/15286258

[25] Braun, K., Bulder, M. and Chabrier, S. (2009) The Course and Outcome of Unilateral Intracranial Arteriopathy in 79 Children with Ischaemic Stroke. Brain, 132, 544-557. https://doi.org/10.1093/brain/awn313

[26] Salih, M.A., Abdel-Gader, A.G., Al-Jarallah, A.A., Kentab, A.Y., Alorainy, I.A., Hassan, H.H., et al. (2006) Stroke in Saudi Children: Epidemiology, Clinical, Features and Risk Factors. Saudi Medical Journal, 27, S12-S20.

[27] Bollaert, P., Vinatier, I., Orlikowski, D. and Meyer, P. (2010) Care Management of Stroke in Adults and Children by Intensive Care Unit (Newborn Excluded), (Excluding Subarachnoid Haemorrhage). Réanimation, 19, 471-478.

https://www.srlf.org/wp-content/uploads/2015/12/2010_recommandations_formali ses_d_experts_prise_en_charge_de_l_accident_vasculaire_cerebral_chez_l_adulte_e t_l_enfant_par_le_reanimateur.pdf 